\title{
What Should the Surgeon Aim for When Performing Computer- Assisted Total Knee Arthroplasty?
}

\author{
By Geert Van Damme, MD, Koen Defoort, MD, Yves Ducoulombier, MD, \\ Francis Van Glabbeek, MD, PhD, Johan Bellemans, MD, PhD, and Jan Victor, MD
}

\section{Introduction}

$\mathrm{S}$ tability of the knee is a complex issue and involves ligaments that behave differently on the medial and lateral side. Correct positioning of the components and adequate soft-tissue balancing are critical steps in successful total knee arthroplasty ${ }^{1}$. A total knee prosthesis that is implanted "too tightly" may cause limited range of motion and compromise patient satisfaction. A total knee replacement that is implanted "too loosely" will be unstable 2 . Medial-lateral instability is the most common type of instability and may result from incompetent collateral ligaments, incomplete correction of a preoperative deformity, or incorrect bone cuts ${ }^{3}$. Separate studies have identified instability as a leading cause of early clinical failure of a primary total knee replacement, resulting in revision within three to five years ${ }^{4,5}$.

It is generally accepted that the surgeon should aim for "some" medial-lateral laxity, but no numerical data are currently available at present to guide the surgeon.
The purpose of this study was to quantify the ligament laxity in a normal nonarthritic knee before and after a standard total knee arthroplasty. A latest-generation fluoroscopy-based spatial navigation system was used to provide the numerical values of medial-lateral, anterior-posterior, and rotational laxity in cadaveric specimens.

\section{Materials and Methods}

Twelve fresh-frozen human cadaveric specimens of lower limbs with nonarthritic knees were used for the study. The age of the individuals at the time of death ranged from forty-seven to eighty-eight years (mean, sixty-eight years).

Prior to the formal testing of the specimens, a pilot project was performed with use of another fresh-frozen human cadaveric lower limb to design the setup. Manual "clinical" testing was compared with instrumented testing with use of a digital dynamometer (Model CH 25 K 50; Kern, Balingen, Germany) with a maximum weighing range of $25 \mathrm{Kg}$ and

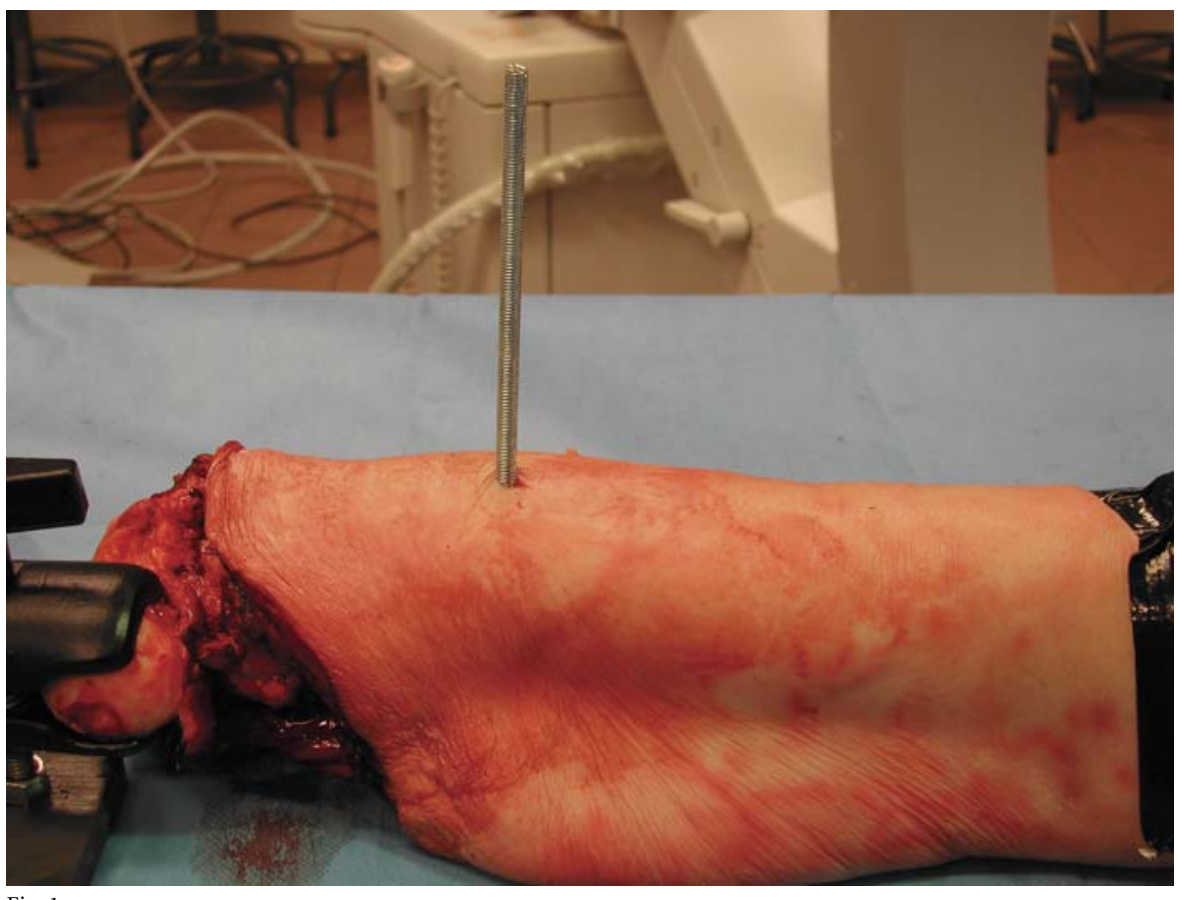

Fig. 1

Preparation of the proximal part of the femur. 


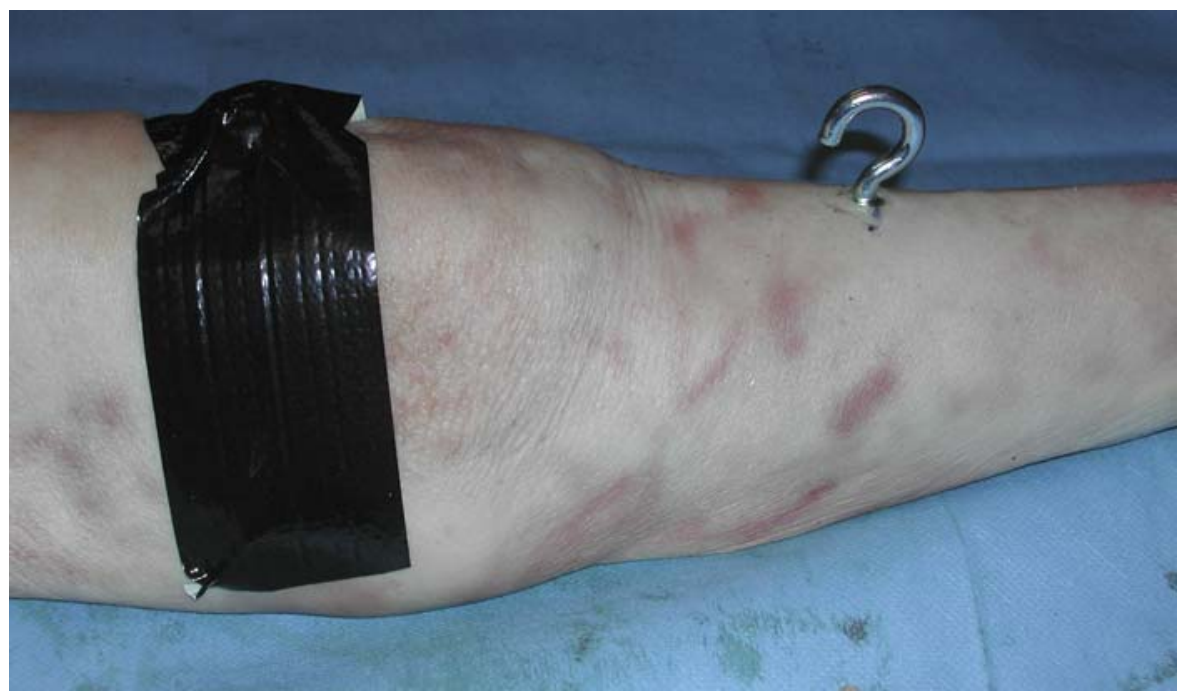

Fig. 2

Preparation of the proximal part of the tibia.

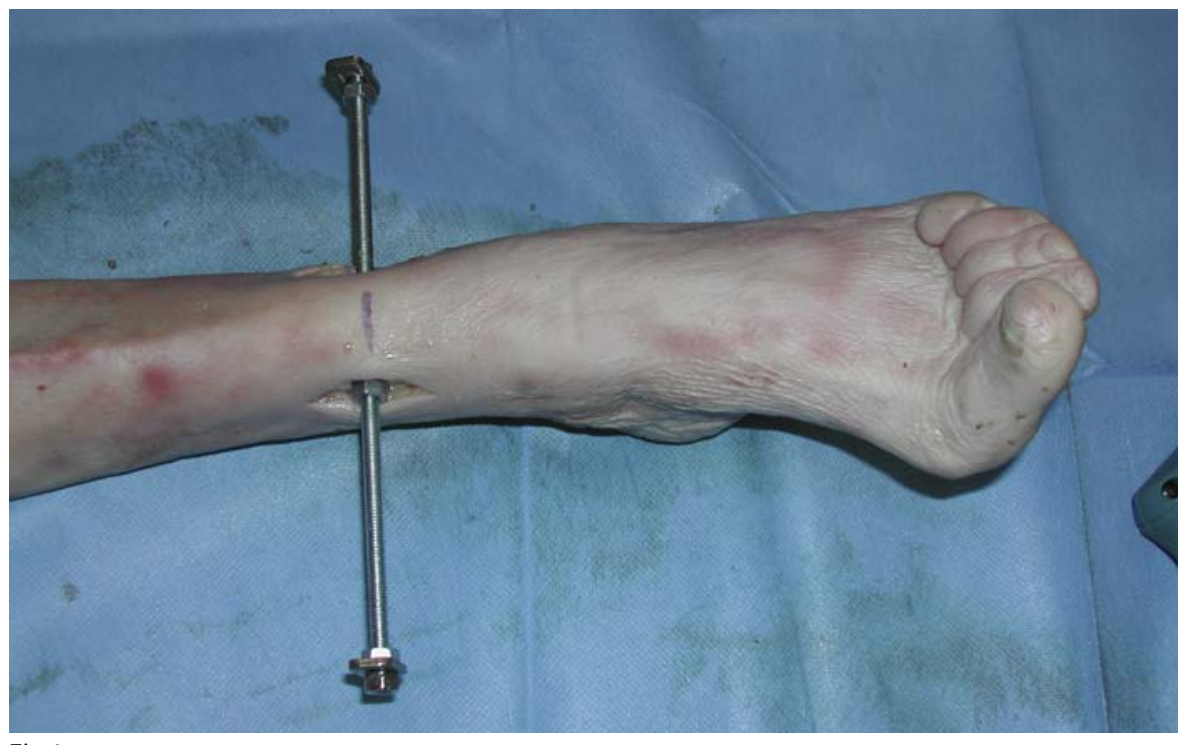

Fig. 3

Preparation of the distal part of the tibia.

readout of $50 \mathrm{~g}$. The reason for this was to standardize the magnitude of forces used for the project. For anterior-posterior laxity testing, an anteriorly directed load of $98 \mathrm{~N}(10 \mathrm{~kg})$ was applied to the proximal aspect of the tibia. Medial-lateral laxity was tested with use of a moment load of $9.8 \mathrm{Nm}$ (4 kg applied $25 \mathrm{~cm}$ distal to the knee joint) to the medial and lateral side of the tibia. Rotational laxity testing was done by applying a $3.92-\mathrm{Nm}$ torque load $(4 \mathrm{~kg}$ at $10 \mathrm{~cm}$ ) to the tibia.

All procedures were undertaken by the same surgeon (G.V.D.), who is experienced in total knee replacement. The order of testing was randomized. The specimens were thawed at room temperature for at least twenty-four hours prior to testing. Before testing, a routine clinical examination was performed to confirm ligamentous stability. A standard antero- posterior radiograph was made to exclude limbs with a pathological condition. After the macroscopic and clinical examination, the specimens were prepared in a standardized fashion. A perfectly round metal ball with a known diameter $(25.38 \mathrm{~mm})$ was attached superolaterally to serve as a reference for radiographic measurements. With use of fluoroscopy, the length of the femur (defined as the distance from the center of the femoral head to the tangential line at the femoral condyles) and the length of the tibia (defined as the distance from a line tangential to the tibial plateau to the tibial dome) were recorded. A 6-mm stainless-steel threaded pin was drilled in an anterior-posterior fashion in the subtrochanteric region of the proximal part of the femur, to control rotation during testing (Fig. 1). The pin was inserted percutaneously 


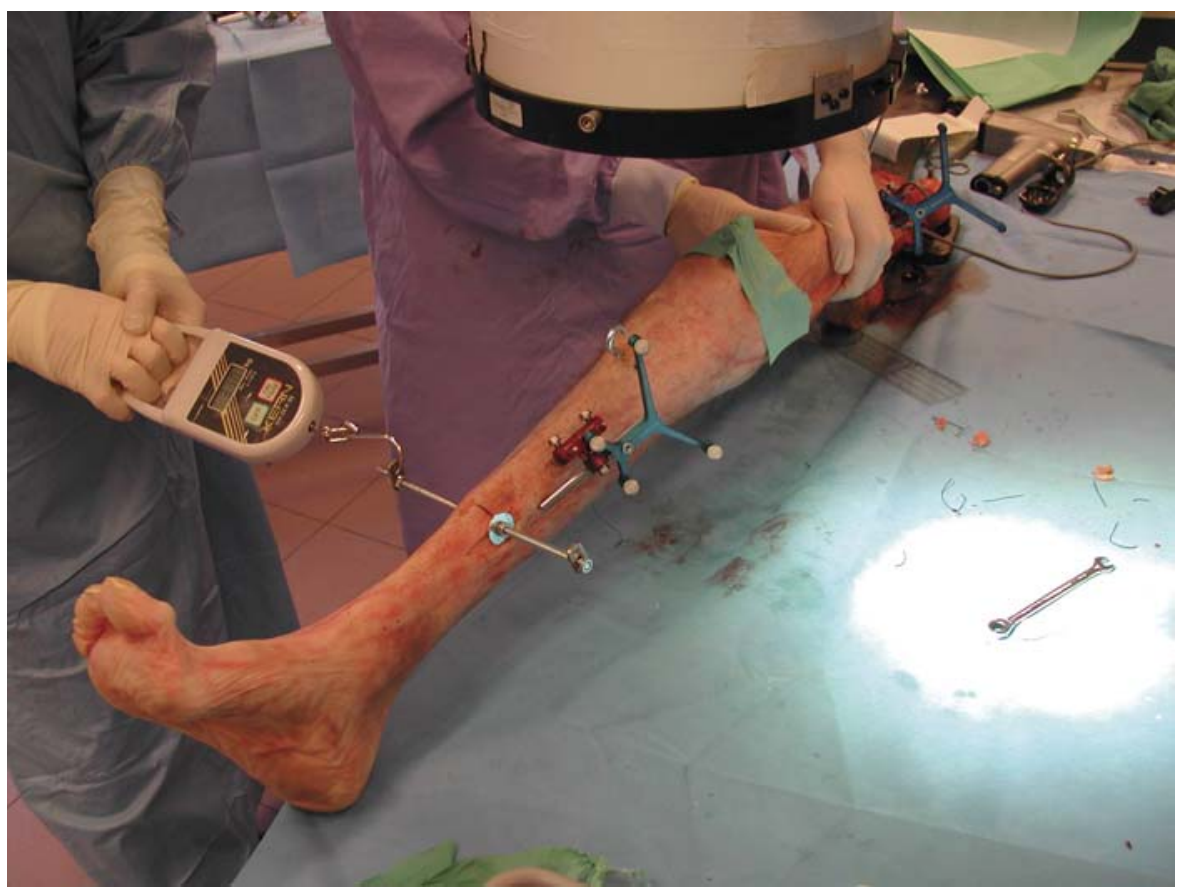

Fig. 4

Instrumented varus-valgus laxity testing.

through a small stab wound. This pin was drilled with the knee held in flexion to avoid tethering of the quadriceps. The quadriceps fibers surrounding the pin were released longitudi- nally over a distance of $2 \mathrm{~cm}$ proximally and distally. After the level of the joint line was determined with fluoroscopy, a hook was screwed in the anterior crest of the proximal part of the

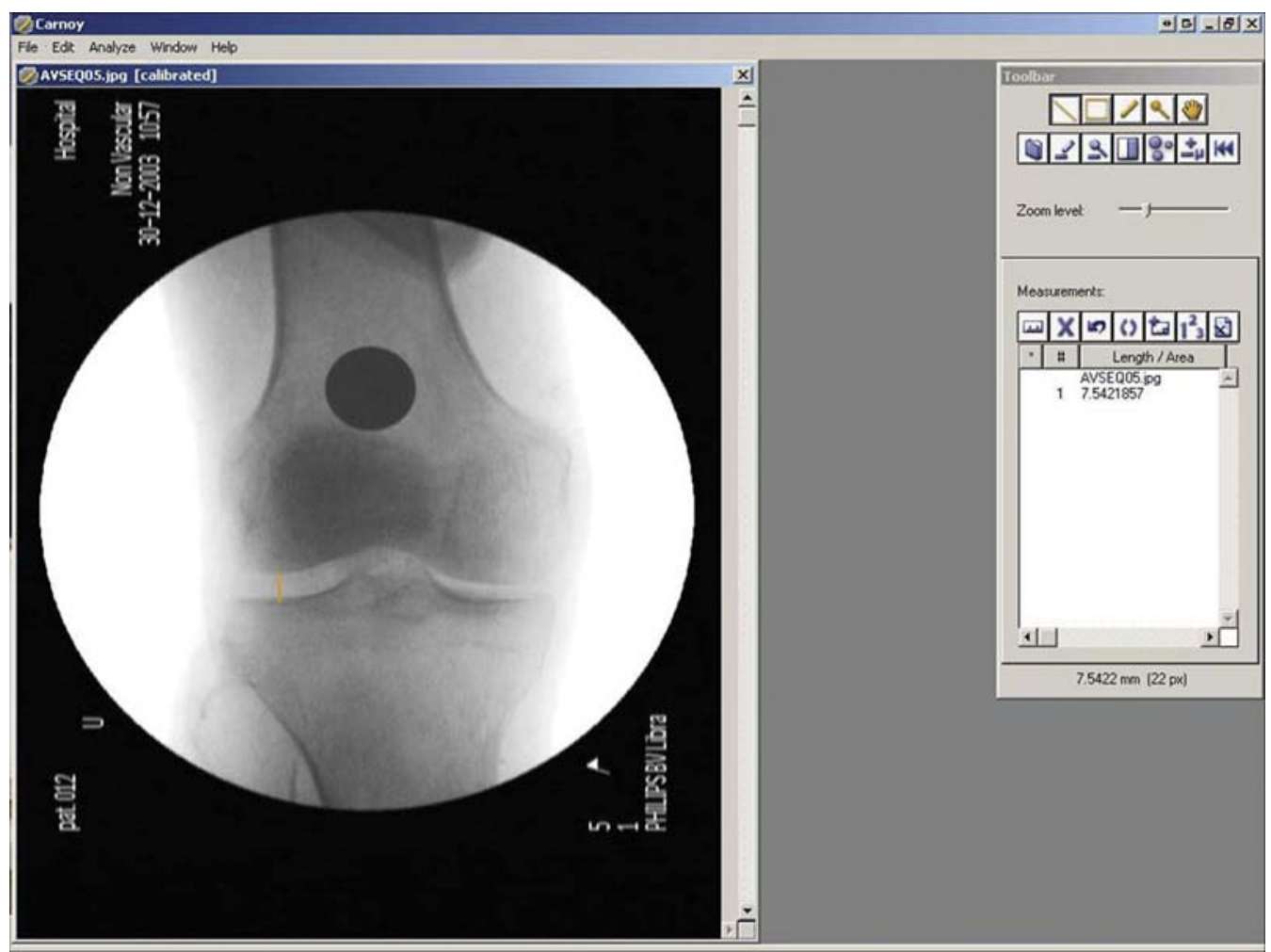

Fig. 5

Digitized joint-line opening measurements. 
The Journal of BOnE \& JOINT Surgery - JBJS.org VOLUME 87-A · SUPPLEMENT 2 2005

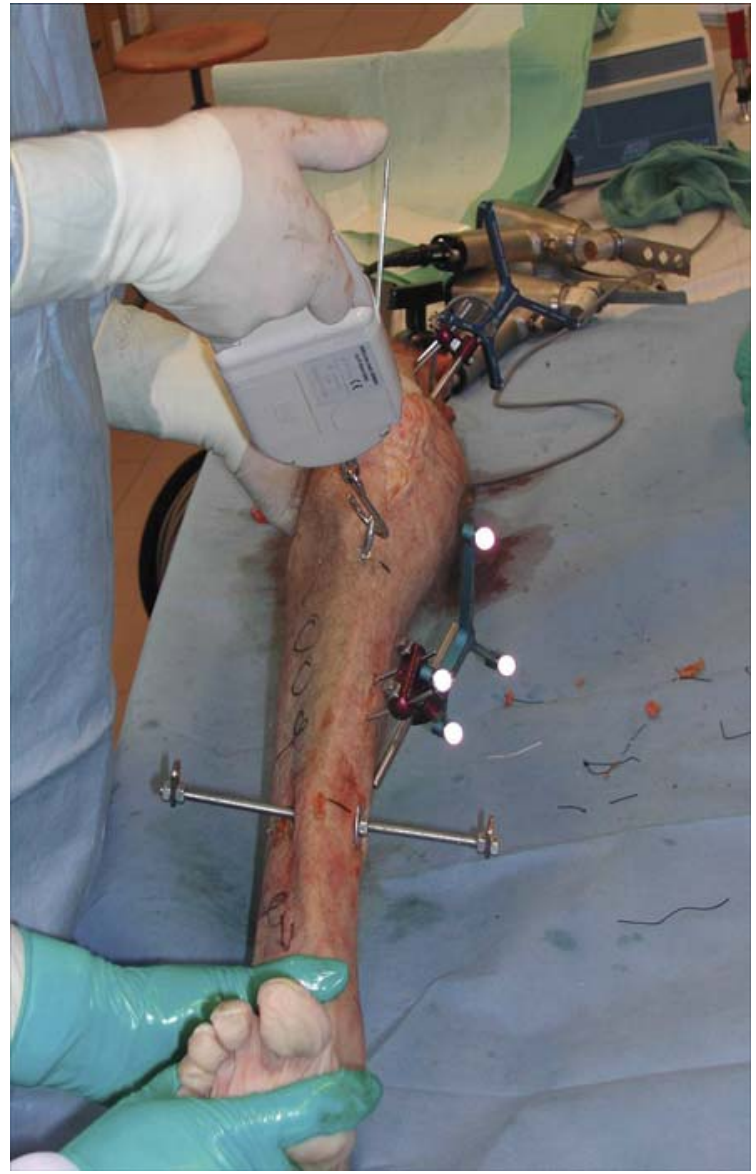

Fig. 6

Instrumented anterior-posterior laxity testing.

tibia $8 \mathrm{~cm}$ distal to the joint line (Fig. 2). The hook was used to apply an anteriorly directed load to the proximal part of the tibia. Finally a 20-cm-long, 6-mm-diameter stainless-steel threaded pin was inserted in a medial-lateral fashion, parallel to the joint line of the ankle. The pin was inserted $25 \mathrm{~cm}$ distal to the joint line of the knee. This pin was placed centrally in the tibia, so that a $10-\mathrm{cm}$-long lever arm was created medially and laterally (Fig. 3). At both ends of this pin, hooks were attached through which loads could be applied for varus-valgus and rotational testing.

After the preparation described above, a series of instrumented laxity tests were performed with use of fluoroscopic images. These tests were used to validate the findings of laxity testing with use of the navigation system.

Varus-valgus laxity was tested with the knee in full extension and $30^{\circ}$ of flexion. A load of $9.8 \mathrm{Nm}$ was applied to the medial and lateral hooks attached to the distal tibial pin (Fig. 4 ), while the femoral rotation was controlled with use of the proximal femoral pin. Fluoroscopic images were made with the knee in the neutral position and in varus and valgus stress, both in extension and in $30^{\circ}$ of flexion. The images were stored digitally and were analyzed with use of the Carnoy image analysis program (Peter Schols, Laboratory of Plant Sys-
What Should the Surgeon Aim for When Performing Computer-Assisted Total Knee Arthroplasty?

tematics, Catholic University of Leuven, Leuven, Belgium) for digital, calibrated measurements (Fig. 5).

At this stage, all preparations were done to use the iON (intraoperative navigation system; Medtronic Surgical Navigation Technologies, Louisville, Colorado). This is a latestgeneration, fluoroscopy-based spatial navigation system, with use of the FluoroKnee software (Smith and Nephew, Memphis, Tennessee, and Medtronic Surgical Navigation Technologies). The fluoroscopic images necessary for determining femoral and tibial axes were acquired and loaded into the system. Two reference frames were attached to the specimen. One active femoral frame was attached with use of two pins medially at $10 \mathrm{~cm}$ proximal to the knee joint. A second, passive, frame was attached to the tibia in the mid-diaphyseal region, also aimed medially. The femoral head was placed in a socketlike clamp, allowing rotation in three degrees of freedom.

The knee was opened with use of a standard medial parapatellar approach. The reference points needed by the navigation system's software were acquired, and the arthrotomy was closed with use of a running suture. After setup of the navigation system, the specimen was tested for anteriorposterior, varus-valgus, and rotational laxity with use of the previously reported standardized loads. These measurements were done in extension and $30^{\circ}$ and $90^{\circ}$ of flexion (Figs. 6 and

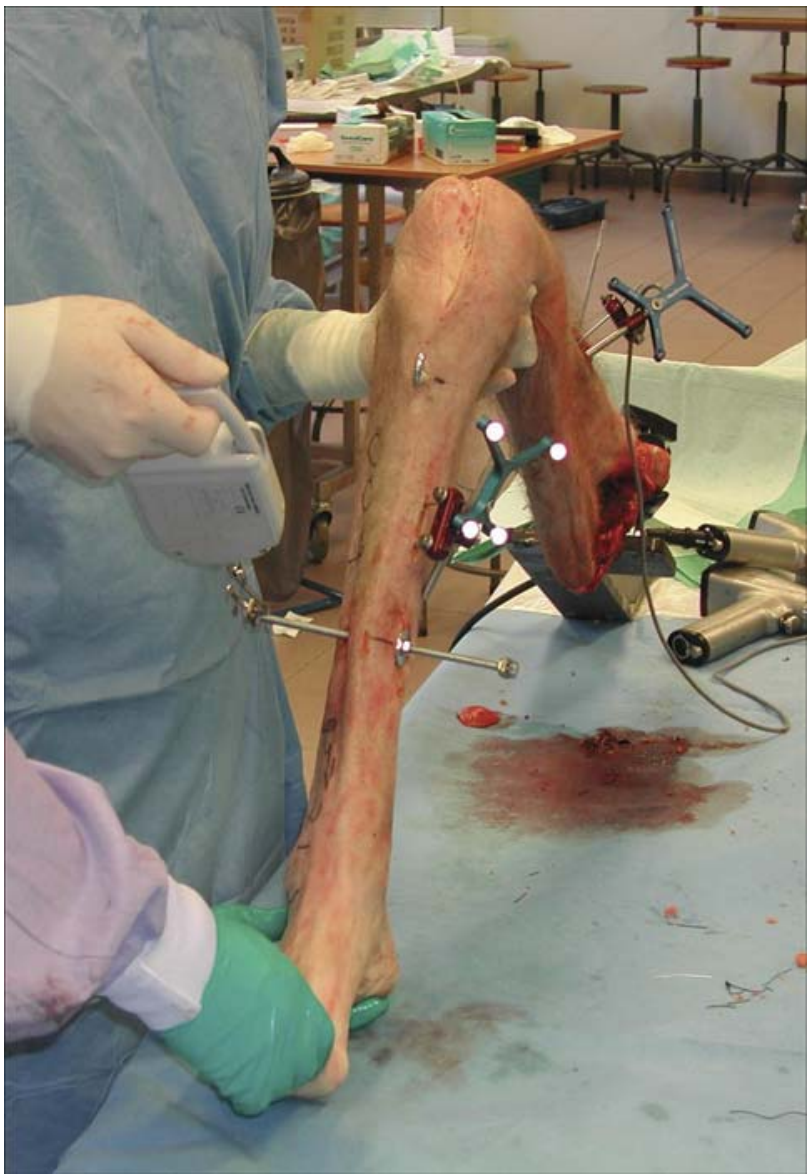

Fig. 7

Instrumented rotational laxity testing. 
The Journal of Bone \& JOINT SURGERY · JBJS.ORG VOLUME 87-A · SUPPLEMENT 2 2005
What Should the Surgeon Aim for When Performing Computer-Assisted Total Knee Arthroplasty?
7). Figure 8 shows an example of a screenshot of the navigation system after a series of testing.

The knee was then reopened and a Genesis II cruciateretaining total knee replacement (Smith and Nephew) was performed without release of the posterior cruciate or collateral ligaments. All implantations were performed with use of the instrumentation provided by the implant manufacturer and the navigation system for correct placement of the implant. Patellar resurfacing was not done. The implants were cemented in place, and the arthrotomy was again closed with use of a running suture. The same array of ligament testing was repeated with the total knee replacement in situ. The same loads were applied, and all values were recorded.

All measurements were stored in an Access XP database (Microsoft, Redmond, Washington) and were analyzed with use of Excel XP (Microsoft) with an Analyse-it plug-in (version 1.71; Analyse-It Software, Leeds, England). Normality tests (Shapiro-Wilk) were done, and Student t tests as well as linear regression were carried out.

\section{Results}

To significant difference ( $\mathrm{p}=0.39$, paired t test) was found 1 between the measurements of the medial joint-line opening on the basis of fluoroscopy compared with navigation- acquired measurements (Pearson correlation, $r=0.52$ ). No significant difference ( $p=0.66$, paired t test) was found between the measurements of the lateral joint-line opening made with fluoroscopy compared with the navigationacquired measurements (Pearson correlation, $r=0.87$ ). As such, the measurements acquired with the navigation system can be considered validated.

Table I summarizes the results of the laxity testing of the native knees with use of the navigation system. The mean values and 95\% confidence intervals are given for the mediallateral, anterior-posterior, and rotational laxity with the knee in extension and in $30^{\circ}$ and $90^{\circ}$ of flexion.

Table II summarizes the results of the same laxity tests after implantation of the cruciate-retaining total knee replacement.

A statistical comparison was done with the results from laxity testing in the native knee. No significant difference could be found between the varus-valgus laxity in the native knee compared with that after the total knee replacement, except for varus stress at $30^{\circ}\left(\mathrm{p}=0.04\right.$, paired t test) and $90^{\circ}(\mathrm{p}=$ 0.001 , paired $t$ test), where laxity was less pronounced in the specimens with the total knee replacement. No significant difference could be found between the anterior-posterior laxity in the native knee compared with that after the total knee re-

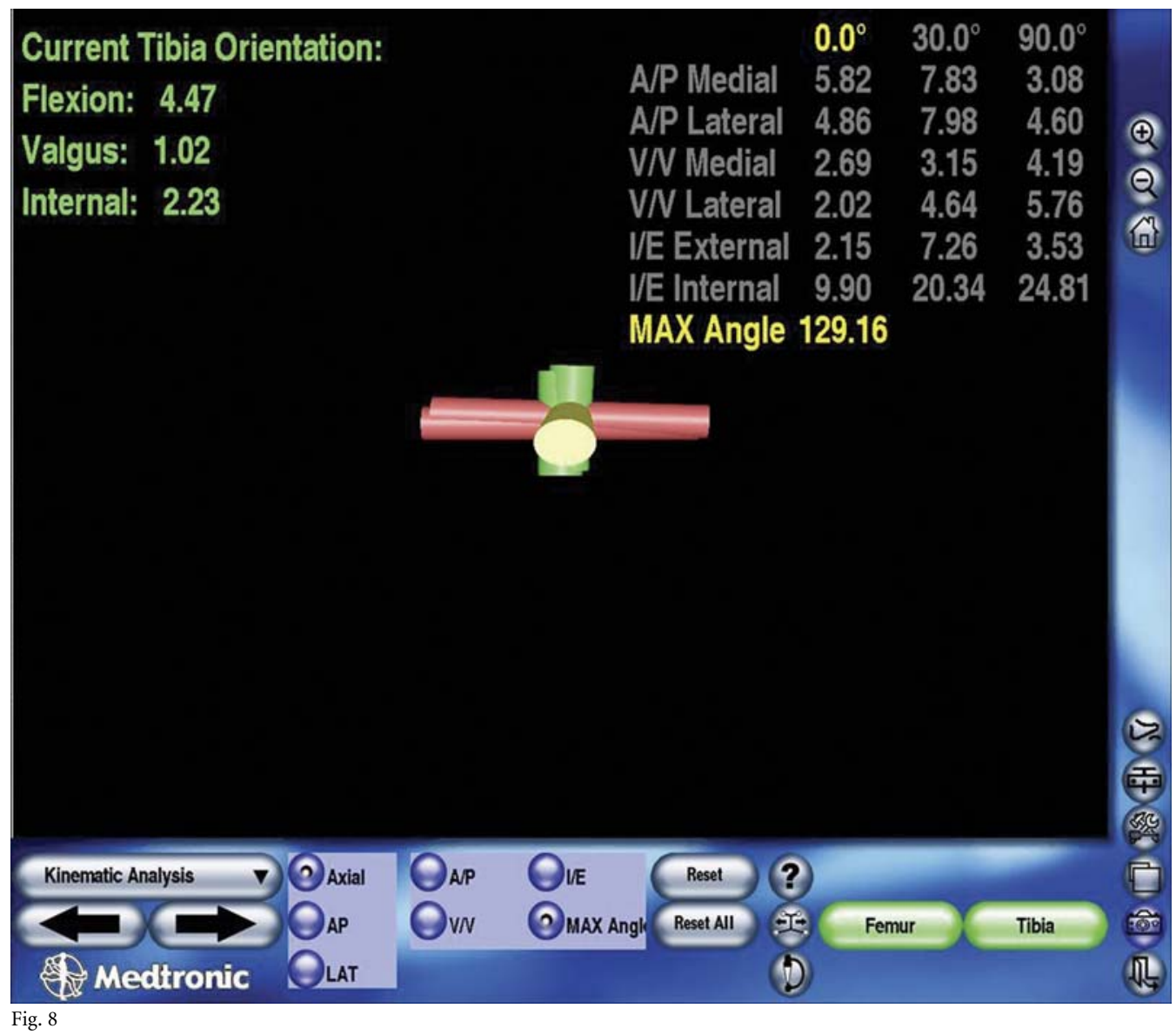

Typical screenshot after a completed array of laxity tests. 
TABLE I Laxity Values of the Native Knee*

\begin{tabular}{|lrrr|}
\hline & \multicolumn{3}{c|}{ Position of the Knee } \\
\cline { 2 - 4 } Measurement & $0^{\circ}$ of Flexion & $30^{\circ}$ of Flexion & $90^{\circ}$ of Flexion \\
\hline Medial joint-line opening $(\mathrm{mm})$ & $2.6 \pm 1.0$ & $5.1 \pm 0.9$ & $7.1 \pm 1.4$ \\
Lateral joint-line opening $(\mathrm{mm})$ & $3.1 \pm 0.8$ & $5.9 \pm 0.7$ & $8.1 \pm 1.0$ \\
Anterior-posterior laxity $(\mathrm{mm})$ & $3.9 \pm 1.0$ & $9.2 \pm 2.2$ & $7.7 \pm 2.0$ \\
Rotational laxity (deg) & $14.0 \pm 3.8$ & $34.0 \pm 2.2$ & $36.0 \pm 3.3$ \\
\hline *The values are given as the mean and the 95\% confidence interval. & & \\
\hline
\end{tabular}

placement $\left(\mathrm{p}=0.51, \mathrm{p}=0.99\right.$, and $\mathrm{p}=0.16$ at $0^{\circ}, 30^{\circ}$, and $90^{\circ}$ of flexion, respectively; paired $t$ test). With regard to rotational laxity, no difference was found with the knee in extension; however, after total knee replacement, the knee had significantly less rotational laxity in $30^{\circ}$ and $90^{\circ}$ of flexion ( $\mathrm{p}=0.006$ and 0.001 , respectively; paired t test).

\section{Discussion}

This study provides the surgeon with quantitative data on 1 the normally expected joint laxity during medial-lateral, anterior-posterior, and rotational stress testing, which can be used as a guideline during ligament balancing when performing total knee arthroplasty.

In previous studies, it was shown that a fluoroscopybased computer-assisted system can substantially reduce the postoperative variability in coronal alignment by eliminating the outliers ${ }^{6}$.

With regard to the laxity values in the native knee, we found that the average medial joint-line opening on valgus stress was $2.6 \mathrm{~mm}$ at $0^{\circ}, 5.1 \mathrm{~mm}$ at $30^{\circ}$, and $7.1 \mathrm{~mm}$ at $90^{\circ}$ of flexion. The average lateral joint-line opening on varus stress was $3.1 \mathrm{~mm}$ at $0^{\circ}, 5.9 \mathrm{~mm}$ at $30^{\circ}$, and $8.1 \mathrm{~mm}$ at $90^{\circ}$ of flexion.

This is consistent with previous findings that the lateral side of the knee is physiologically more lax, and as a consequence the flexion gap in normal knees may not be rectan$\operatorname{gular}^{7-9}$. In a recent study of twenty normal knees that were assessed with magnetic resonance imaging, Tokuhara et al. ${ }^{10}$ found a discrepancy of the flexion gap in the medial and lateral tibiofemoral joint of $4.6 \mathrm{~mm}$ with a tilt of $5^{\circ}$ in the femur and tibia. When a varus stress was applied, the lateral joint gap opened by a mean (and standard deviation) of $6.7 \pm 1.9 \mathrm{~mm}$, whereas the medial joint gap opened by only a mean of $2.1 \pm$ $1.1 \mathrm{~mm}$. The amount of stress was not standardized in that study and was affected by several factors including the weight of the leg and the mobility of the hip.

In the present study, we found the average anteriorposterior laxity to be $3.9 \mathrm{~mm}$ at $0^{\circ}, 9.2 \mathrm{~mm}$ at $30^{\circ}$, and $7.7 \mathrm{~mm}$ at $90^{\circ}$ of flexion. This supports previous reports of maximum laxity at $30^{\circ}$ in studies by Fukubayashi et al. ${ }^{11}$ and Gollehon et al. ${ }^{12}$. This observation also provides support for performing the Lachman test for anterior-posterior instability at $30^{\circ}$ of knee flexion.

Mean rotational laxity increased from $14^{\circ}$ in extension to $34^{\circ}$ at $30^{\circ}$ of flexion and to $36^{\circ}$ at $90^{\circ}$ of flexion. This is in line with results of previous studies by both Hsieh and Walker ${ }^{13}$ and Blankevoort et al. ${ }^{14}$.

After implantation of the total knee replacement, the laxity values were not significantly different from those in the normal knee except for lateral laxity at $30^{\circ}$ and $90^{\circ}$ of flexion, with less laxity after the arthroplasty. However, after total knee replacement, laxity measurements on the lateral side were comparable with those on the medial side, demonstrating a mediolaterally balanced total knee replacement. In comparison, Ishii et al. ${ }^{15}$ and Matsuda and Ishii $^{16}$ reported $4^{\circ}$ of coronal laxity in abduction and adduction with a posterior cruciate-retaining prosthesis at $0^{\circ}$ to $20^{\circ}$ flexion with use of a Telos arthrometer.

After total knee replacement, the average anteriorposterior laxity was $4.1 \mathrm{~mm}$ at $0^{\circ}, 9.2 \mathrm{~mm}$ at $30^{\circ}$, and $10.3 \mathrm{~mm}$ at $90^{\circ}$ of flexion. Remarkably, this pattern did not mimic the increased laxity at $30^{\circ}$ that is usually seen in normal knees. The same pattern after total knee replacement was seen in

TABLE II Laxity Values with the Cruciate-Retaining Total Knee Implant*

\begin{tabular}{|lrrr|} 
& \multicolumn{3}{c|}{ Position of the Knee } \\
\cline { 2 - 4 } Measurement & $0^{\circ}$ of Flexion & $30^{\circ}$ of Flexion & $90^{\circ}$ of Flexion \\
\hline Medial joint-line opening $(\mathrm{mm})$ & $2.4 \pm 0.5$ & $4.3 \pm 1.3$ & $5.8 \pm 1.5$ \\
Lateral joint-line opening $(\mathrm{mm})$ & $2.2 \pm 0.7$ & $4.7 \pm 0.8$ & $5.6 \pm 1.1$ \\
Anterior-posterior laxity $(\mathrm{mm})$ & $4.1 \pm 1.2$ & $9.2 \pm 2.4$ & $10.3 \pm 3.4$ \\
Rotational laxity (deg) & $11.1 \pm 2.4$ & $26.1 \pm 4.5$ & $30.3 \pm 5.8$ \\
\hline *The values are given as the mean and the 95\% confidence interval. & & \\
\hline
\end{tabular}


The Journal of Bone \& JoINT SURGERY $\cdot$ JBJS.ORG Volume 87 -A $\cdot$ SUPplement $2 \cdot 2005$
What Should the Surgeon Aim for When Performing Computer-Assisted Total Knee Arthroplasty? studies of laxity in knees under low compressive forces ${ }^{17}$. However, in the study by Matsuda and Ishii ${ }^{16}$, this pattern was seen in knees managed with a total knee arthroplasty that had a deficient posterior cruciate ligament compared with those with an intact ligament, which followed the normal pattern. That study supported the finding that the increase in posterior cruciate ligament tension with flexion might affect the anteriorposterior laxity in posterior cruciate ligament-retaining knees. The increased laxity found in our study may have been due to the fact that we applied only an anteriorly directed force. At $90^{\circ}$ of flexion, the more pronounced laxity may have been due to gravitational forces causing an initially more posterior position of the tibia.

The average rotational laxity after total knee implantation was $11.1^{\circ}$ in extension, $26.1^{\circ}$ at $30^{\circ}$ of flexion, and $30.3^{\circ}$ at $90^{\circ}$ of flexion. Compared with our findings in nonreplaced knees, this rotational laxity was substantially less at $30^{\circ}$ and $90^{\circ}$ of flexion, but not in extension.

\section{Conclusions}

The present cadaveric study provides the knee surgeon 1 with the "normal" values for knee laxity obtained with a fluoroscopy-based latest-generation spatial navigation system. When the goal of total knee arthroplasty is to restore the natural anatomy as closely as possible, then the ortho- paedic surgeon should aim for these laxity values.

Additional work should be done to validate these findings with clinical results from total knee replacements implanted with use of these "normal" values. Furthermore, more studies on "in vivo" testing of knee laxity with use of navigation systems are necessary to obtain more reliable values.

NOTES: The authors acknowledge Professor Hilde Bortier for giving us the opportunity to do this cadaveric study in the anatomy laboratory of the University of Antwerp, and we thank Mr. WilMistiaen, MD, for his help during the process and Mr. Philippe Danckaert for his invaluable technical support.

Corresponding author:

Geert Van Damme, MD,

Department of Orthopaedic Surgery, A.Z. Sint-Lucas, Sint-Lucaslaan 29, B-8310 Brugge, Belgium. E-mail address: vandamme.geert@skynet.be

The authors did not receive grants or outside funding in support of their research or preparation of this manuscript. One or more of the authors received payments or other benefits or a commitment or agreement to provide such benefits from a commercial entity (Smith \& Nephew [Memphis, TN]). No commercial entity paid or directed, or agreed to pay or direct, any benefits to any research fund, foundation, educational institution, or other charitable or nonprofit organization with which the authors are affiliated or associated.

doi:10.2106/JBJS.E.00447

\section{References}

1. Whiteside LA. Soft tissue balancing: the knee. J Arthroplasty. 2002;17 (4 Suppl 1): 23-7.

2. Zalzal P, Papini M, Petruccelli D, de Beer J, Winemaker MJ. An in vivo biomechanical analysis of the soft-tissue envelope of osteoarthritic knees. J Arthroplasty. 2004;19:217-23.

3. Fehring TK, Valadie AL. Knee instability after total knee arthroplasty. Clin Orthop Relat Res. 1994;299:157-62.

4. Fehring TK, Odum S, Griffin WL, Mason JB, Nadaud M. Early failures in total knee arthroplasty. Clin Orthop Relat Res. 2001;392:315-8.

5. Sharkey PF, Hozack WJ, Rothman RH, Shastri S, Jacoby SM. Why are tota knee arthroplasties failing today? Clin Orthop Relat Res. 2002;404:7-13.

6. Victor J, Hoste D. Image-based computer-assisted total knee arthroplasty leads to lower variability in coronal alignment. Clin Orthop Relat Res. 2004;428:131-9.

7. Markolf KL, Mensch JS, Amstutz HC. Stiffness and laxity of the knee-the contributions of the supporting structures. A quantitative in vitro study. J Bone Joint Surg Am. 1976;58:583-94.

8. Seering WP, Piziali RL, Nagel DA, Schurman DJ. The function of the primary ligaments of the knee in varus-valgus and axial rotation. J Biomech. 1980;13:785-94.

9. Moore TM, Meyers MH, Harvey JP Jr. Collateral ligament laxity of the knee. Long-term comparison between plateau fractures and normal. J Bone
Joint Surg Am. 1976;58:594-8.

10. Tokuhara $Y$, Kadoya $Y$, Nakagawa S, Kobayashi A, Takaoka K. The flexion gap in normal knees: an MRI study. J Bone Joint Surg Br. 2004;86:1133-6.

11. Fukubayashi T, Torzilli PA, Sherman MF, Warren RF. An in vitro biomechanical evaluation of anterior-posterior motion of the knee. Tibial displacement, rotation, and torque. J Bone Joint Surg Am. 1982;64:258-64.

12. Gollehon DL, Torzilli PA, Warren RF. The role of the posterolateral and cruciate ligaments in the stability of the human knee. A biomechanical study. J Bone Joint Surg Am. 1987;69:233-42.

13. Hsieh $\mathrm{HH}$, Walker PS. Stabilizing mechanisms of the loaded and unloaded knee joint. J Bone Joint Surg Am. 1976;58:87-93.

14. Blankevoort $L$, Huiskes $R$, de Lange $A$. The envelope of passive knee joint motion. J Biomech. 1988;21:705-20.

15. Ishii $Y$, Matsuda $Y$, Ishii $R$, Sakata S, Omori G. Coronal laxity in extension in vivo after total knee arthroplasty. J Orthop Sci. 2003;8:538-42.

16. Matsuda $Y$, Ishii $Y$. In vivo laxity of low contact stress mobile-bearing prostheses. Clin Orthop Relat Res. 2004;419:138-43.

17. Luger E, Sathasivam S, Walker PS. Inherent differences in the laxity and stability between the intact knee and total knee replacements. The Knee. 1997; $4: 7-14$ 